\title{
Prognostic significance of TPX2 and NIBP in esophageal cancer
}

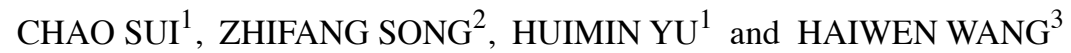 \\ Departments of ${ }^{1}$ Medical Oncology, ${ }^{2}$ Oncology and ${ }^{3}$ Thoracic Surgery, Weihai Central Hospital, \\ Weihai, Shandong 264400, P.R. China
}

Received April 8, 2019; Accepted July 10, 2019

DOI: 10.3892/ol.2019.10747

\begin{abstract}
The expression of targeting protein for Xenopus kinesin-like protein 2 (TPX2) and NIK-IKK- $\beta$ binding protein (NIBP) in patients with esophageal cancer were investigated. A total of 250 samples of cancer tissue and 250 samples of adjacent normal tissue were collected from 250 patients who underwent radical resection of esophageal cancer in Weihai Central Hospital from March 2011 to February 2014. RT-qPCR was used to detect the relative expression of TPX2 and NIBP. The relative expression of TPX2 and NIBP in esophageal cancer tissues was statistically higher than those in adjacent normal tissues $(\mathrm{P}<0.05)$. TPX2 and NIBP levels in tumor tissues with lymph node metastasis were significantly higher than those in tissues without lymph node metastasis $(\mathrm{P}<0.05)$. There was a significant difference in the relative expression of TPX2 and NIBP in different degrees of infiltration $(\mathrm{P}<0.05)$. Tissues with a TPX2 level equal to or higher than the average TPX2 level (1.465) were divided into TPX2 high expression group, while tissues with a TPX2 level below the average were divided into TPX2 low expression group. The 5-year overall survival rate of TPX2 high expression group was significantly lower than that of TPX2 low expression group $(\mathrm{P}<0.05)$. Tissues with a NIBP level equal to or higher than the average NIBP level (0.498) were included in the NIBP high expression group, while tissues with a NIBP level below the average were included in the NIBP low expression group. The 5-year overall survival rate of NIBP high expression group was significantly lower than that of NIBP low expression group $(\mathrm{P}<0.05)$. TPX2, NIBP, TNM staging, lymph node metastasis, and degree of infiltration were independent prognostic factors affecting overall survival $(\mathrm{P}<0.05)$. In conclusion, owing to their high expression in esophageal cancer tissues, TPX2 and NIBP are potentially important biomarkers for the evaluation of TNM stage, metastasis, and prognosis of esophageal cancer.
\end{abstract}

Correspondence to: Dr Haiwen Wang, Department of Thoracic Surgery, Weihai Central Hospital, 3 West Mishan East Road, Weihai, Shandong 264400, P.R. China

E-mail: ud462q@163.com; sc789ok@163.com

Key words: TPX2, NIBP, esophageal cancer, clinical pathology, prognosis

\section{Introduction}

Esophageal cancer, one of the top 10 malignant tumors, has a high morbidity that ranks 8th among all malignant tumors (1). Generally, surgery and chemoradiotherapy are the main clinical treatments for esophageal cancer. At present, surgery is the optimal option for patients suitable for surgical resection. However, it leads to a low 5-year survival rate of 15-20\% (2) and a great possibility of pulmonary complications and anastomotic leakage (3). Considering the great toxic side effects that chemoradiotherapy brings, the exploration of a method to improve the postoperative survival and provide accurate postoperative treatment is in an urgent need.

In recent years, a high expression level of Xenopus kinesin-like protein 2 (TPX2) in patients with non-small cell lung cancer (4), cervical (5), and oral cancer (6) compared to healthy individuals has been reported, suggesting the possible involvement of TPX2 in the occurrence and development of a variety of tumors. Chang et al (7) found that the high expression of TPX2 in cervical cancer cells causes a more active proliferation of cancer cells and predicts the deterioration of cervical cancer, leading to speculation that the high expression of TPX2 may be a tumorigenic mechanism. Lowering the expression of TPX2 can effectively inhibit the growth and invasion of tumor cells (8). NIK-IKK- $\beta$ binding protein (NIBP), which has gained attention in the medical field, is highly expressed in various tumor tissues such as colon (9), gastric (10), and esophageal (11) cancer, and has proved to promote the proliferation and invasion of tumor cells (12). In their study on NIBP expression in colon cancer, $\mathrm{Xu}$ et al (9) found that NIBP is overexpressed in colon cancer, and patients with high NIBP expression have much lower overall survival than patients with lower levels of NIBP. They also showed that the expression level of NIBP is an important prognostic factor in colon cancer patients.

There is little research on the expression of TPX2 and NIBP in esophageal cancer and their roles in prognosis. The expression of TPX2 and NIBP in esophageal cancer was investigated, and their clinical significance in the occurrence, development, and prognosis of esophageal cancer was explored in this study.

\section{Patients and methods}

General information. Tissue samples from 250 patients who received radical resection of esophageal cancer in Weihai Central 
Table I. Primer sequences of TPX2, NIBP, and GAPDH.

\begin{tabular}{lll}
\hline Genes & \multicolumn{1}{c}{ Forward primers } & \multicolumn{1}{c}{ Reverse primers } \\
\hline TPX2 & 5'-ACCTTGCCCTACTAAGATT-3' & 5'-AATGTGGCACAGGTTGAGC-3' \\
NIBP & 5'-GAACTGCCTTAGCCCTGAAGACAT-3' & 5'-AGCCTTGATGCACGCTTCC-3' \\
GAPDH & 5'-GCACCGTCAAGGTGAGAAC-3' & 5'-TGGTGAAGACGCCAGTGGA-3'
\end{tabular}

TPX2, Xenopus kinesin-like protein 2; NIBP, NIK-IKK- $\beta$ binding protein.

Hospital (Weihai, China) from March 2011 to February 2014 were collected. The same size of esophageal cancer tissue and adjacent cancer tissue were taken from the patients. Histopathological typing showed 198 cases of squamous cell carcinoma, 29 cases of adenocarcinoma, 13 cases of undifferentiated carcinoma, and 10 cases of adenosquamous carcinoma.

Inclusion criteria were: patients diagnosed with esophageal cancer by pathology; patients with no history of anti-tumor therapy such as radiotherapy and chemotherapy before the radical surgery for esophageal cancer; patients with complete clinical data. The TNM staging referred to the Union for International Cancer Control (UICC) Cancer Staging Manual (13). Exclusion criteria were: patients combined with severe liver and kidney dysfunction, hypertension, diabetes, or other malignant tumors; patients with mental disorders or communication disorders. This study was approved by the Ethics Committee of Weihai Central Hospital. Informed consent was signed by the patients or the guardians.

Reagents and equipment. StepOnePlus Real-Time PCR System was purchased from Thermo Fisher Scientific, Inc. DR5000 UV-V spectrophotometer was purchased by HACH. SYBR-Green Quantitative RT-qPCR Kit (cat. no. QR0100) was purchased from Takara. TRIzol extraction kit was purchased from Wuhan Chundu Biotechnology Co., Ltd. (cat. no. CDLG-4396). The reverse transcription kit was purchased from GeneCopoeia, Inc. Rabbit anti-human TPX2 polyclonal antibody (cat. no. PAB11993) and rabbit anti-human NIBP polyclonal antibody (cat. no. PAB0321) were purchased from Abnova. HRP-labeled rabbit secondary antibody (cat. no. 6401-05) was purchased from BioVision. Rabbit anti-human GAPDH polyclonal antibody (cat. no. GV357911) was purchased from Shanghai Yiji Industial Co., Ltd. The design and synthesis of TPX2, NIBP, and GAPDH internal reference primers were from Takara Biotechnology Co., Ltd. The primer sequences are shown in Table I.

\section{Experimental methods}

$R T-q P C R$. Cancer tissues and adjacent normal tissues $(4 \mathrm{~cm}$ away or farther from the edge of cancer tissue) were collected from each patient during the surgical resection, and then cut into cubes $(0.5 \mathrm{~cm} \times 0.5 \mathrm{~cm} \times 0.5 \mathrm{~cm})$ before storing at $-80^{\circ} \mathrm{C}$ in liquid-nitrogen. $3 \mathrm{~mm}^{3}$ esophageal cancer tissues and $3 \mathrm{~mm}^{3}$ adjacent normal tissues were ground in liquid-nitrogen, and the tissue suspension was taken to extract total RNA according to the TRIzol extraction kit. The density and purity of total RNA were detected by DR5000 UV-visible spectrophotometer. Then reverse transcription was performed based
Table II. General clinical and pathological data of patients with esophageal cancer [n (\%)].

Factors

Case no. $(\%)$

Sex

Male

$168(67.20)$

Female

$82(32.80)$

Age (years)

$<58$

$52(20.80)$

$\geq 58$

198 (79.20)

Tumor diameter $(\mathrm{cm})$

$<5.0$

$183(73.20)$

$\geq 5.0$

67 (26.80)

Tumor location

Upper thoracic portion

$68(27.20)$

Middle thoracic portion

$128(51.20)$

Posterior thoracic portion

$54(21.60)$

TNM stage

I

II

$110(44.00)$

$88(35.20)$

III

$32(12.80)$

IV

$20(8.00)$

Lymph node metastasis

Yes

$72(28.80)$

No

$178(71.20)$

Histopathological typing

Squamous cell carcinoma

198 (79.20)

Adenocarcinoma

$29(11.60)$

Undifferentiated carcinoma

$13(5.20)$

Adenosquamous carcinoma

$10(4.00)$

on the instructions of the kit. Conditions for reverse transcription reaction were: $1 \mathrm{~h}$ at $37^{\circ} \mathrm{C}, 5 \mathrm{~min}$ at $85^{\circ} \mathrm{C}$ for inactivation, and the reaction was terminated at $4^{\circ} \mathrm{C}$. The synthesized cDNA samples were stored in a refrigerator at $-20^{\circ} \mathrm{C}$. PCR reaction system (a total volume of $25 \mu \mathrm{l}$ ): $5 \mu \mathrm{l}$ CTV cDNA, $1 \mu 1$ upstream primer, $1.25 \mu \mathrm{l}$ downstream primer, $1 \mu 125 \mathrm{mM}$ $\mathrm{MgCl}_{2}, 2.5 \mathrm{p} \mu \mathrm{l}$ 10X PCR buffer, $0.3 \mu \mathrm{l}$ Taq enzyme and $13.95 \mu \mathrm{l}$ water. PCR Premix, $50 \mathrm{ng}$ double-distilled water, $50 \mathrm{ng}$ ROX Dye, and $200 \mathrm{~nm}$ primers. GAPDH was used as the internal reference gene, and the reaction conditions were: 35 cycles in $1 \mathrm{~min}$ of $95^{\circ} \mathrm{C}$ for $4 \mathrm{~min}, 95^{\circ} \mathrm{C}$ for $30 \mathrm{sec}, 58^{\circ} \mathrm{C}$ for $30 \mathrm{sec}$ and $72^{\circ} \mathrm{C}$, and extension at $72^{\circ} \mathrm{C}$ for $10 \mathrm{~min}$. The 
Table III. Expression of TPX2 and NIBP genes in esophageal cancer (mean \pm SD).

\begin{tabular}{lccr}
\hline Groups & No. & TPX2 & NIBP \\
\hline Cancer tissues & 250 & $1.465 \pm 0.136$ & $0.498 \pm 0.112$ \\
Adjacent normal tissues & 250 & $0.923 \pm 0.114$ & $0.244 \pm 0.104$ \\
t-value & - & 48.291 & 26.276 \\
P-value & - & $<0.001$ & $<0.001$ \\
\hline
\end{tabular}

TPX2, Xenopus kinesin-like protein 2; NIBP, NIK-IKK- $\beta$ binding protein.

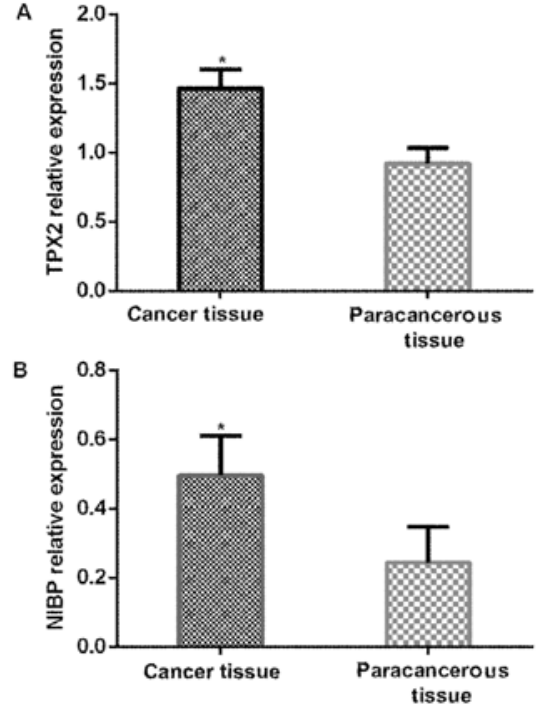

Figure 1. Expression of TPX2 and NIBP in esophageal cancer. (A) The expression of TPX2 in esophageal cancer tissues. RT-qPCR results show that the relative expression of TPX2 in esophageal cancer tissues was significantly higher than that in adjacent normal tissues. (B) The expression of NIBP in esophageal cancer tissues. RT-qPCR results show that the relative expression of NIBP in esophageal cancer tissues was significantly higher than that in adjacent normal tissues. ${ }^{*} \mathrm{P}<0.05$, compared with adjacent normal tissues. TPX2, Xenopus kinesin-like protein 2; NIBP, NIK-IKK- $\beta$ binding protein.

experiment was repeated 3 times. The data were analyzed with $2^{-\Delta \mathrm{Cq}}$ method (14).

Western blot analysis. The total protein of the tissue was frozen with liquid nitrogen, and the protein concentration was determined by the BCA method. TPX2 protein concentration detection: electrophoresis was performed by $6 \%$ SDS-PAGE electrophoresis. Denatured protein sample $(30 \mu \mathrm{l})$ was separated and transferred to a PVDF membrane. The PVDF membrane was removed and washed three times with TBST (T1082) for 15 min each time. Then, 5\% skim milk powder was used for blocking for $1 \mathrm{~h}$. TPX2 primary antibody $(1: 1,500)$ and GAPDH primary antibody $(1: 3,000)$ were added and incubated overnight at $4^{\circ} \mathrm{C}$ in a refrigerator. The next day, they were washed with PBST 3 times, and then incubated with HRP rabbit secondary antibody $(1: 5,000)$ at $20^{\circ} \mathrm{C}$ for $1 \mathrm{~h}$. After washing 3 times, ECL chemiluminescence was used to visualize, and the images were preserved. The operation of NIBP protein concentration detection was similar to that of the TPX2 protein concentration detection, and the NIBP primary antibody dilution was (1:100).
Follow-up. The follow-up was performed every 3 months via telephone or visit to 250 patients, lasting for 5 years until January 2019. The overall survival time referred to the time from the first day after the surgery to the last day of follow-up or the day of non-survival.

Statistical analysis. Statistical analysis was performed using SPSS 21.0 (IBM Corp.). Chi-square test was used to compare the enumeration data between groups. The independent samples t-test was used to compare the measurement data between the two groups. The paired t-test was used for comparison before and after operation. The Kaplan-Meier method was used to separately establish survival curves for TPX2, NIBP high and low expression populations. The log-rank test was used to measure the difference in the survival curves between the two groups. The Cox regression equation was used to detect independent prognostic factors for esophageal cancer. The correlation between NIBP and TPX2 was analyzed by Pearson's correlation analysis. $\mathrm{P}<0.05$ was considered to indicate a statistically significant difference.

\section{Results}

General information. A total of 250 samples of adjacent normal tissues were obtained from 250 esophageal cancer patients with complete clinical data (including 168 male patients and 82 females, aged 30-83 years). Of the 250 subjects whose tumor diameter ranged from 3.2 to $6.3 \mathrm{~cm}, 183$ cases had a tumor diameter $<5.0 \mathrm{~cm}$, and 67 cases had a tumor diameter $\geq 5.0 \mathrm{~cm} \mathrm{(15);} 52$ cases were $<58$ years of age, 198 cases were $\geq 58$ years; 68 cases had their tumors located in the upper thoracic portion, 128 cases in the middle thoracic portion, and 54 cases in the posterior thoracic portion; 110 cases were TNM stage I, 88 cases were stage II, 32 cases were stage III, and 20 cases had reached stage IV. There were 198 cases of squamous cell carcinoma, 29 cases of adenocarcinoma, 13 cases of undifferentiated carcinoma, and 10 cases of adenosquamous carcinoma (Table II).

Expression of TPX2 and NIBP genes in esophageal cancer. The relative expression of TPX2 gene in esophageal cancer tissues was significantly higher than that in adjacent tissues $(\mathrm{P}<0.001)$. The relative expression of NIBP gene in cancer tissues was significantly higher than that in adjacent tissues $(\mathrm{P}<0.001)$ (Table III and Fig. 1). 
Table IV. Expression of TPX2 and NIBP protein in esophageal cancer (mean \pm SD).

\begin{tabular}{lccr}
\hline Groups & No. & TPX2 & NIBP \\
\hline Cancer tissues & 250 & $0.673 \pm 0.078$ & $0.248 \pm 0.044$ \\
Adjacent normal tissues & 250 & $0.223 \pm 0.035$ & $0.124 \pm 0.029$ \\
t-value & - & 82.225 & 37.205 \\
P-value & - & $<0.001$ & $<0.001$ \\
\hline
\end{tabular}

TPX2, Xenopus kinesin-like protein 2; NIBP, NIK-IKK- $\beta$ binding protein.

Table V. Relationship between clinicopathological parameters and relative expression of TPX2 in cancer tissues (mean \pm SD).

\begin{tabular}{|c|c|c|c|c|}
\hline Clinicopathological parameters & No. & TPX2 relative expression & $\mathrm{t} / \mathrm{F}$ & P-value \\
\hline Sex & & 0.287 & 0.775 & \\
\hline Male & 168 & $1.454 \pm 0.076$ & & \\
\hline Female & 82 & $1.451 \pm 0.081$ & & \\
\hline Age (years) & & 0.387 & 0.699 & \\
\hline$<58$ & 52 & $1.448 \pm 0.071$ & & \\
\hline$\geq 58$ & 198 & $1.452 \pm 0.065$ & & \\
\hline Tumor diameter (cm) & & 0.355 & 0.723 & \\
\hline$<5.0$ & 183 & $1.455 \pm 0.056$ & & \\
\hline$\geq 5.0$ & 67 & $1.458 \pm 0.067$ & & \\
\hline Tumor location & & 0.913 & 0.403 & \\
\hline Upper thoracic portion & 68 & $1.445 \pm 0.055$ & & \\
\hline Middle thoracic portion & 128 & $1.452 \pm 0.068$ & & \\
\hline Posterior thoracic portion & 54 & $1.461 \pm 0.069$ & & \\
\hline TNM stage & & 25.410 & $<0.001$ & \\
\hline I & 110 & $1.416 \pm 0.073$ & & \\
\hline II & 88 & $1.445 \pm 0.043^{\mathrm{a}}$ & & \\
\hline III & 32 & $1.494 \pm 0.067^{\mathrm{a}, \mathrm{b}}$ & & \\
\hline IV & 20 & $1.524 \pm 0.060^{\mathrm{a}-\mathrm{c}}$ & & \\
\hline Lymph node metastasis & & 4.261 & $<0.001$ & \\
\hline Yes & 92 & $1.457 \pm 0.098$ & & \\
\hline No & 158 & $1.413 \pm 0.065$ & & \\
\hline Histopathological typing & & & 0.563 & 0.642 \\
\hline Squamous cell carcinoma & 198 & $1.475 \pm 0.051$ & & \\
\hline Adenocarcinoma & 29 & $1.468 \pm 0.046$ & & \\
\hline Undifferentiated carcinoma & 13 & $1.487 \pm 0.061$ & & \\
\hline Adenosquamous carcinoma & 10 & $1.464 \pm 0.053$ & & \\
\hline Degree of infiltration & & & 22.597 & $<0.001$ \\
\hline Mucous layer & 45 & $1.428 \pm 0.061$ & & \\
\hline Muscular layer & 38 & $1.436 \pm 0.057$ & & \\
\hline Fibrous membranes & 150 & $1.508 \pm 0.076^{\mathrm{d}, \mathrm{e}}$ & & \\
\hline Surrounding tissue & 17 & $1.518 \pm 0.066^{\mathrm{d}, \mathrm{e}}$ & & \\
\hline
\end{tabular}

${ }^{\mathrm{a}} \mathrm{P}<0.001$, compared with stage I; ${ }^{\mathrm{b}} \mathrm{P}<0.001$, compared with stage II; ${ }^{\mathrm{C}}<0.001$, compared with stage III; ${ }^{\mathrm{d}} \mathrm{P}<0.001$, compared with the mucous layer; ${ }^{\mathrm{P}}<0.001$, compared with the muscular layer. TPX2, Xenopus kinesin-like protein 2.

Expression of TPX2 and NIBP protein in esophageal cancer. The relative expression of TPX2 protein in esophageal cancer tissues was significantly higher than that in adjacent tissues, with statistically significant difference $(\mathrm{P}<0.05)$. The relative expression of NIBP protein in esophageal cancer tissues was significantly higher than that 
Table VI. Relationship between clinicopathological parameters and relative expression of NIBP in cancer tissues (mean \pm SD).

\begin{tabular}{|c|c|c|c|c|}
\hline Clinicopathological parameters & No. & NIBP relative expression & $\mathrm{t} / \mathrm{F}$ & P-value \\
\hline Sex & & 0.399 & 0.690 & \\
\hline Male & 168 & $0.478 \pm 0.076$ & & \\
\hline Female & 82 & $0.482 \pm 0.071$ & & \\
\hline Age (years) & & 0.333 & 0.739 & \\
\hline$<58$ & 52 & $0.474 \pm 0.081$ & & \\
\hline$\geq 58$ & 198 & $0.478 \pm 0.076$ & & \\
\hline Tumor diameter $(\mathrm{cm})$ & & 0.085 & 0.933 & \\
\hline$<5.0$ & 183 & $0.480 \pm 0.092$ & & \\
\hline$\geq 5.0$ & 67 & $0.475 \pm 0.086$ & & \\
\hline Tumor location & & 0.066 & 0.936 & \\
\hline Upper thoracic portion & 68 & $0.475 \pm 0.054$ & & \\
\hline Middle thoracic portion & 128 & $0.473 \pm 0.051$ & & \\
\hline Posterior thoracic portion & 54 & $0.478 \pm 0.059$ & & \\
\hline TNM stage & & 38.900 & $<0.001$ & \\
\hline I & 110 & $0.438 \pm 0.043$ & & \\
\hline II & 88 & $0.469 \pm 0.053^{\mathrm{a}}$ & & \\
\hline III & 32 & $0.501 \pm 0.068^{\mathrm{a}, \mathrm{b}}$ & & \\
\hline IV & 20 & $0.558 \pm 0.042^{\mathrm{a}-\mathrm{c}}$ & & \\
\hline Lymph node metastasis & & 6.828 & $<0.001$ & \\
\hline Yes & 92 & $0.512 \pm 0.068$ & & \\
\hline No & 158 & $0.455 \pm 0.061$ & & \\
\hline Histopathological typing & & & 2.062 & 0.106 \\
\hline Squamous cell carcinoma & 198 & $0.489 \pm 0.067$ & & \\
\hline Adenocarcinoma & 29 & $0.466 \pm 0.056$ & & \\
\hline Undifferentiated carcinoma & 13 & $0.455 \pm 0.043$ & & \\
\hline Adenosquamous carcinoma & 10 & $0.478 \pm 0.053$ & & \\
\hline Degree of infiltration & & & 13.876 & $<0.001$ \\
\hline Mucous layer & 45 & $0.467 \pm 0.044$ & & \\
\hline Muscular layer & 38 & $0.478 \pm 0.051$ & & \\
\hline Fibrous membranes & 150 & $0.502 \pm 0.048^{\mathrm{d}, \mathrm{e}}$ & & \\
\hline Surrounding tissue & 17 & $0.545 \pm 0.052^{\mathrm{d}-\mathrm{f}}$ & & \\
\hline
\end{tabular}

${ }^{\mathrm{a}} \mathrm{P}<0.001$, compared with that of stage I; ${ }^{\mathrm{b}} \mathrm{P}<0.001$, compared with that of stage II; ${ }^{\mathrm{P}}<0.001$, compared with that of stage III; ${ }^{\mathrm{d}} \mathrm{P}<0.001$, compared with the mucous layer; ${ }^{\mathrm{e}} \mathrm{P}<0.001$, compared with the muscular layer; ${ }^{\mathrm{f}} \mathrm{P}<0.001$, compared with the fibrous membrane. NIBP, NIK-IKK- $\beta$ binding protein.

in adjacent tissues, with statistically significant difference $(\mathrm{P}<0.001)$ (Table IV).

Association between TPX2 expression and clinicopathological features. TPX2 levels in esophageal cancer patients with different sex, age, tumor diameter, tumor location and histopathological typing were not significantly different $(\mathrm{P}>0.05)$. Patients with different TNM stages had significantly different TPX2 levels $(\mathrm{P}<0.05)$. The relative expression levels of TPX2 in different levels of infiltration were significantly different $(\mathrm{P}<0.001)$. The TPX2 levels in tumor tissues with lymph node metastasis were significantly higher than those in tissues without lymph node metastasis $(\mathrm{P}<0.001)$ (Table V).
Association between NIBP expression and clinicopathological features. NIBP levels in esophageal cancer patients with different sex, age, tumor diameter, tumor location, and histopathological typing were not significantly different $(\mathrm{P}>0.05)$. Patients with different TNM stages had significantly different NIBP levels $(\mathrm{P}<0.001)$. The relative expression of NIBP in different levels of infiltration was significantly different $(\mathrm{P}<0.05)$. The NIBP levels in tumor tissues with lymph node metastasis were significantly higher than those in tissues without lymph node metastasis $(\mathrm{P}<0.001)$ (Table VI).

Survival of patients with esophageal cancer. According to the average values of relative expression of TPX2 (1.465) and 
Table VII. Results of single factor analysis of prognosis in patients with esophageal cancer.

\begin{tabular}{|c|c|c|c|c|}
\hline Groups & No. & 5-year survival case (no.) & $\chi^{2}$ & P-value \\
\hline Age (years) & & & 2.118 & 0.146 \\
\hline$<58$ & 52 & 26 & & \\
\hline$\geq 58$ & 198 & 104 & & \\
\hline Sex & & & 0.030 & 0.863 \\
\hline Male & 168 & 88 & & \\
\hline Female & 82 & 42 & & \\
\hline Tumor diameter $(\mathrm{cm})$ & & & 1.205 & 0.272 \\
\hline$<5$ & 183 & 99 & & \\
\hline$\geq 5$ & 67 & 31 & & \\
\hline Tumor location & & & 0.829 & 0.661 \\
\hline Upper thoracic portion & 68 & 37 & & \\
\hline Middle thoracic portion & 128 & 63 & & \\
\hline Posterior thoracic portion & 54 & 30 & & \\
\hline TNM stage & & & 10.963 & 0.012 \\
\hline I & 110 & 68 & & \\
\hline II & 88 & 44 & & \\
\hline III & 32 & 12 & & \\
\hline IV & 20 & 6 & & \\
\hline Degree of infiltration & & & 13.676 & 0.003 \\
\hline Mucous layer & 45 & 31 & & \\
\hline Muscular layer & 38 & 25 & & \\
\hline Fibrous membranes & 150 & 69 & & \\
\hline Surrounding tissue & 17 & 5 & & \\
\hline TPX2 expression & & & 26.010 & $<0.001$ \\
\hline High & 131 & 48 & & \\
\hline Low & 119 & 82 & & \\
\hline NIBP expression & & & 36.511 & $<0.001$ \\
\hline High & 156 & 58 & & \\
\hline Low & 94 & 72 & & \\
\hline Histopathological typing & & & 1.835 & 0.607 \\
\hline Squamous cell carcinoma & 198 & 107 & & \\
\hline Adenocarcinoma & 29 & 12 & & \\
\hline Undifferentiated carcinoma & 13 & 6 & & \\
\hline Adenosquamous carcinoma & 10 & 5 & & \\
\hline
\end{tabular}

TPX2, Xenopus kinesin-like protein 2; NIBP, NIK-IKK- $\beta$ binding protein.

NIBP (0.498) in patients with esophageal cancer, 131 patients with a TPX2 level $\geq 1.465$ were divided into TPX2 high expression group, 119 patients with a TPX2 level $<1.465$ were divided into TPX2 low expression group; 156 patients with a NIBP level $\geq 0.498$ were divided into NIBP high expression group, 94 patients with a NIBP level $<0.498$ were divided into NIBP low expression group. The 5-year overall survival rate of TPX2 high expression group was 36.64\% (48/131), statistically lower than that of TPX2 low expression group which was $68.91 \%(82 / 119)(\mathrm{P}=0.004$, log-rank test); NIBP high expression group had a 5-year overall survival rate of $37.18 \%$ (58/156), statistically lower than that of TPX2 low expression group at $76.60 \%(72 / 94)(\mathrm{P}<0.001$, log-rank test) (Fig. 2).
Analysis of factors related to prognosis of esophageal cancer. Univariate analysis of general factors and clinicopathological factors showed that different age, sex, tumor diameter, tumor location and pathological type were not prognostic factors affecting the overall survival of patients with esophageal cancer $(\mathrm{P}>0.05)$. TNM staging, degree of infiltration, TPX2 expression and NIBP expression may be the prognostic factors affecting the overall survival of patients with esophageal cancer $(\mathrm{P}<0.001)$ (Table VII). The meaningful indicators in the univariate analysis were included in the Cox proportional hazard model, and the multivariate analysis was performed by the stepwise regression method. The variable entry criterion was 0.05 and the rejection criterion was 0.1 . The results showed that TPX2, NIBP, TNM staging, lymph node metas- 
Table VIII. Multivariate analysis of prognosis in patients with esophageal cancer.

Multiple variables

Factors

HR $(95 \% \mathrm{CI}) \quad$ P-value

TPX2 (high expression vs. low expression)

$2.945(1.344-4.575)$

0.012

NIBP (high expression vs. low expression)

$2.391(1.358-3.830)$

0.009

TNM stage

$1.369(1.037-1.807)$

0.026

Lymph node metastasis (yes vs. no)

$2.097(1.536-3.502)$

0.076

Degree of infiltration

$1.286(1.057-1.564)$

0.012

TPX2, Xenopus kinesin-like protein 2; NIBP, NIK-IKK- $\beta$ binding protein.

A

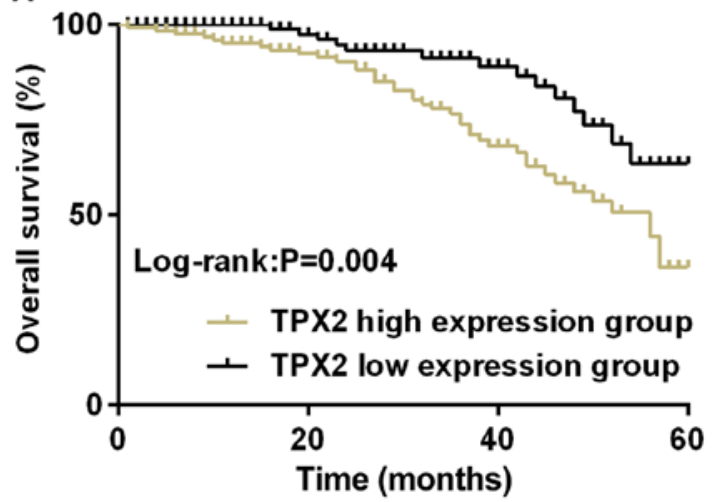

B

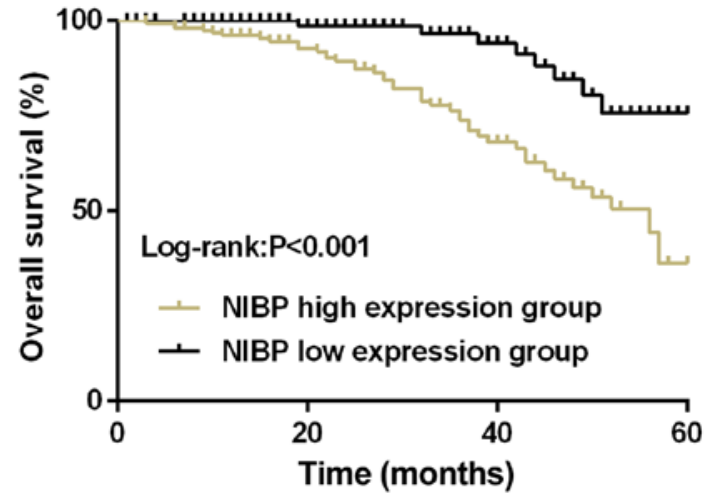

Figure 2. Survival of patients with esophageal cancer. (A) The 5-year overall survival rate of TPX2 high expression group was much lower than that of TPX2 low expression group $(\mathrm{P}<0.05)$. (B) The 5-year overall survival rate of NIBP high expression group was much lower than that of NIBP low expression group $(\mathrm{P}<0.001)$. TPX2, Xenopus kinesin-like protein 2; NIBP, NIK-IKK- $\beta$ binding protein.

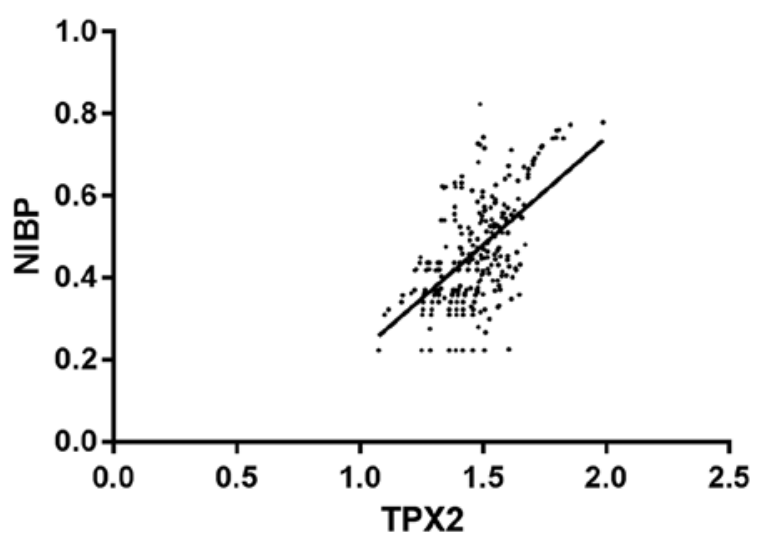

Figure 3. Correlation analysis of TPX2 and NIBP. Pearson's analysis showed that there is a positive correlation between TPX2 expression and NIBP expression in esophageal cancer tissues, with significant difference $(\mathrm{P}<0.001)$. TPX2, Xenopus kinesin-like protein 2; NIBP, NIK-IKK- $\beta$ binding protein.

tasis, and degree of infiltration were independent prognostic factors $(\mathrm{P}<0.05)$ (Table VIII).

Correlation analysis of TPX2 and NIBP. Pearson's analysis showed that there was a positive correlation between TPX2 expression and NIBP expression in esophageal cancer tissues, with significant difference $(r=0.575$, $\mathrm{P}<0.001$ ) (Fig. 3).

\section{Discussion}

Due to only few clinical symptoms, low screening rate for esophageal cancer, and patients' poor awareness of medical care, patients with esophageal cancer are not correctly diagnosed until they reach the middle or advanced cancer stage, and thus miss the treatment opportunity of surgical resection (16). Owing to individual differences, patients with esophageal cancer of the same clinical pathology type sometimes have different conditions and survival rates after treatment. Therefore, the search for effective prognostic markers is of great significance for the stratified treatment of esophageal cancer patients, and it has important clinical value to improve the postoperative survival time (17).

In recent years in-depth studies on TPX2 and NIBP have been conducted. Increasingly, abnormal expression of TPX2 and NIBP has been identified in various types of cancer such as non-small cell lung cancer (18), liver cancer (19), and gastric cancer (20), which has certain value in the prognosis evaluation. In this study, TPX2 also presented a high expression in tissues with lymph node metastasis. The upregulated TPX2 expression indicates more active tumor cell growth and division and stronger ability of invasion; therefore the tumor development may be contained through the control of TPX2 expression. Hsu et al (21) found that high expression of TPX2 is an independent prognostic factor for 
patients with esophageal cancer, and knocking down TPX2 levels can significantly suppress cancer cell proliferation. Liu et al (22) discovered that high expression of TPX2 is a risk factor for lymph node metastasis of esophageal carcinoma, and TPX2 can be used as a biomarker for early diagnosis and prognosis of esophageal cancer. In this study, TPX2 expression was upregulated in cancer tissues, and TPX2 expression was closely related to tumor TNM grade, lymph node metastasis and degree of infiltration; TPX2 was a risk factor for lymph node metastasis of esophageal cancer, similar to the above results. This indicates that TPX2 can be used as a biomarker for the diagnosis and prognosis of esophageal cancer. Liu et al (23) showed that inhibition of TPX2 gene expression can effectively inhibit the invasion and metastasis of esophageal cancer cell line EC9706, promote tumor cell apoptosis, and may be a new way to treat esophageal cancer. This further validates that the suppression on tumor progression can be achieved via the control of TPX2 expression. Many studies demonstrated that the positive expression of NIBP in gastric cancer (10), colon cancer (9), lung cancer (24) is significantly higher than that in normal tissues. Overexpression of NIBP in tumor tissues proved by such studies is consistent with the results of these studies, suggesting that NIBP is excessively expressed in cancer tissues and is involved in the occurrence and development of esophageal cancer. The study of NIBP in colon cancer cells by Qin et al (25) suggested that NIBP may accelerate the secretion of MMP-2 and MMP-9 by activating $\mathrm{NF}-\mathrm{kB}$ signaling pathway, thereby promoting the invasion and metastasis of colon cancer cells. In the present study, the 5-year survival analysis of esophageal cancer patients revealed that patient with low expression of TPX2 and NIBP enjoyed a higher survival rate than patients with high TPX2 and NIBP expression. The univariate Cox regression analysis showed that TPX2, NIBP, TNM staging, lymph node metastasis and the degree of infiltration were prognostic factors that may affect the overall survival of patients with esophageal cancer. The results of the multivariate analysis of the Cox model showed that TPX2, NIBP, TNM typing, lymph node metastasis and degree of infiltration were the prognostic factors affecting the overall survival of patients with esophageal cancer. According to the results of this study, the high expression of TPX2 and NIBP promotes the development of esophageal cancer. TNM staging is a related factor affecting the prognosis of patients with esophageal cancer and can represent the degree of tumor deterioration. The occurrence of lymph node metastasis implies further spread of tumor cells. A more severe cancer results in a poorer prognosis. The findings of this study suggest that TPX2 and NIBP are potential predictors of prognosis of patients.

Pearson's correlation analysis was used to analyze the correlation between TPX2 expression level and NIBP expression level in esophageal cancer tissues. The results showed that TPX2 expression level was positively correlated with NIBP expression level in esophageal cancer tissues. There may be a synergistic effect between TPX2 and NIBP to promote the development of esophageal cancer.

The present study confirmed that the high expression of NIBP and TPX2 can promote the development and progression of esophageal cancer. However, there are limitations in this study. The relationship between NIBP and TPX2 was not observed from the viewpoint of basic research, and the mechanism of NIBP and TPX2 in esophageal cancer was not explored.

In conclusion, NIBP and TPX2 are highly expressed in esophageal cancer tissues, and they may have the capability of predicting the prognosis of esophageal cancer. At present, research is scarce on the mechanism of TPX2 and NIBP in esophageal cancer. TPX2 and NIBP are expected to become therapeutic targets for esophageal cancer.

\section{Acknowledgements}

Not applicable.

\section{Funding}

No funding was received.

\section{Availability of data and materials}

The datasets used and/or analyzed during the present study are available from the corresponding author on reasonable request.

\section{Authors' contributions}

CS wrote the manuscript. CS and ZS performed PCR. HY analyzed and interpreted the patients' data. HW helped with statistical analysis. All the authors read and approved the final manuscript.

\section{Ethics approval and consent to participate}

The present study was approved by the Ethics Committee of Weihai Central Hospital (Weihai, China). Patients who participated in this study, had complete clinical data. Signed informed consents were obtained from the patients or guardians.

\section{Patient consent for publication}

Not applicable.

\section{Competing interests}

The authors declare that they have no competing interests.

\section{References}

1. Arnold M, Laversanne M, Brown LM, Devesa SS and Bray F: Predicting the future burden of esophageal cancer by histological subtype: International trends in incidence up to 2030. Am J Gastroenterol 112: 1247-1255, 2017.

2. Mao A: Interventional therapy of esophageal cancer. Gastrointest Tumors 3: 59-68, 2016

3. Sunpaweravong S, Ruangsin S, Laohawiriyakamol S, Mahattanobon S and Geater A: Prediction of major postoperative complications and survival for locally advanced esophageal carcinoma patients. Asian J Surg 35: 104-109, 2012.

4. Schneider MA, Christopoulos P, Muley T, Warth A, Klingmueller U, Thomas M, Herth FJ, Dienemann H, Mueller NS, Theis $F$ and Meister M: AURKA, DLGAP5, TPX2, KIF11 and CKAP5: Five specific mitosis-associated genes correlate with poor prognosis for non-small cell lung cancer patients. Int J Oncol 50: 365-372, 2017. 
5. Zhang H, Zhang T, You Z and Zhang Y: Positive surgical margin, HPV persistence, and expression of both TPX2 and PD-L1 are associated with persistence/recurrence of cervical intraepithelial neoplasia after cervical conization. PLoS One 10: e0142868, 2015.

6. Zhao X, Sun S, Zeng X and Cui L: Expression profiles analysis identifies a novel three-mRNA signature to predict overall survival in oral squamous cell carcinoma. Am J Cancer Res 8 450-461, 2018

7. Chang H, Wang J, Tian Y, Xu J, Gou X and Cheng J: The TPX2 gene is a promising diagnostic and therapeutic target for cervical cancer. Oncol Rep 27: 1353-1359, 2012.

8. Jiang T, Sui D, You D, Yao S, Zhang L, Wang Y, Zhao J and Zhang Y: MiR-29a-5p inhibits proliferation and invasion and induces apoptosis in endometrial carcinoma via targeting TPX2. Cell Cycle 17: 1268-1278, 2018.

9. Xu CY, Qin MB, Tan L, Liu SQ and Huang JA: NIBP impacts on the expression of E-cadherin, CD44 and vimentin in colon cancer via the NF- $\kappa \mathrm{B}$ pathway. Mol Med Rep 13: 5379-5385, 2016.

10. Fu ZH, Liu SQ, Qin MB, Huang JA, Xu CY, Wu WH, Zhu LY, Qin N and Lai MY: NIK and IKK $\beta$ binding protein contributes to gastric cancer chemoresistance by promoting epithelial mesenchymal transition through the NFKB signaling pathway. Oncol Rep 39: 2721-2730, 2018.

11. Cheng C, Zhou Y, Li H, Xiong T, Li S, Bi Y, Kong P, Wang F, Cui $\mathrm{H}, \mathrm{Li} \mathrm{Y}$, et al: Whole-genome sequencing reveals diverse models of structural variations in esophageal squamous cell carcinoma. Am J Hum Genet 98: 256-274, 2016.

12. Zhang Y, Liu S, Wang H, Yang W, Li F, Yang F, Yu D, Ramsey FV, Tuszyski GP and $\mathrm{Hu}$ W: Elevated NIBP/TRAPPC9 mediates tumorigenesis of cancer cells through $\mathrm{NF \kappa B}$ signaling. Oncotarget 6: 6160-6178, 2015.

13. Phillips WA, Russell SE, Ciavarella ML, Choong DY, Montgomery KG, Smith K, Pearson RB, Thomas RJ and Campbell IG: Mutation analysis of PIK3CA and PIK3CB in esophageal cancer and Barrett's esophagus. Int J Cancer 118: 2644-2646, 2006.

14. Livak KJ and Schmittgen TD: Analysis of relative gene expression data using real-time quantitative PCR and the 2(-Delta Delta C(T)) Method. Methods 25: 402-408, 2001.

15. Cao HH, Zhang SY, Shen JH, Wu ZY, Wu JY, Wang SH, Li EM and $\mathrm{Xu}$ LY: A three-protein signature and clinical outcome in esophageal squamous cell carcinoma. Oncotarget 6: 5435-5448, 2015.

16. Davis JN, Medbery C, Sharma S, Pablo J, Kimsey F, Perry D, Muacevic A and Mahadevan A: Stereotactic body radiotherapy for centrally located early-stage non-small cell lung cancer or lung metastases from the RSSearch $(\circledR)$ patient registry. Radiat Oncol 10: 113, 2015.
17. Yodying H, Matsuda A, Miyashita M, Matsumoto S, Sakurazawa N, Yamada M and Uchida E: Prognostic significance of neutrophil-to-lymphocyte ratio and platelet-to-lymphocyte ratio in oncologic outcomes of esophageal cancer: A systematic review and meta-analysis. Ann Surg Oncol 23: 646-654, 2016.

18. Choi YL, Takeuchi K, Soda M, Inamura K, Togashi Y, Hatano S, Enomoto M, Hamada T, Haruta H, Watanabe H, et al: Identification of novel isoforms of the EML4-ALK transforming gene in non-small cell lung cancer. Cancer Res 68: 4971-4976, 2008.

19. Wang J, Liu Z, Dou C, Han S, Li C, Tu K and Yang W: miR-491 inhibits the proliferation, invasion and migration of hepatocellular carcinoma cell via down-regulating TPX2 expression. Xi Bao Yu Fen Zi Mian Yi Xue Za Zhi 32: 512-517, 2016 (In Chinese).

20. Sasaki N, Morisaki T, Hashizume K, Yao T, Tsuneyoshi M Noshiro H, Nakamura K, Yamanaka T, Uchiyama A, Tanaka M and Katano M: Nuclear factor-kappaB p65 (RelA) transcription factor is constitutively activated in human gastric carcinoma tissue. Clin Cancer Res 7: 4136-4142, 2001.

21. Hsu PK, Chen HY, Yeh YC, Yen CC, Wu YC, Hsu CP, Hsu WH and Chou TY: TPX2 expression is associated with cell proliferation and patient outcome in esophageal squamous cell carcinoma. J Gastroenterol 49: 1231-1240, 2014.

22. Liu HC, Zhang Y, Wang XL, Qin WS, Liu YH, Zhang L and Zhu CL: Upregulation of the TPX2 gene is associated with enhanced tumor malignance of esophageal squamous cell carcinoma. Biomed Pharmacother 67: 751-755, 2013.

23. Liu HC, Zhang GH, Liu YH, Wang P, Ma JF, Su LS, Li SL, Zhang L and Liu JW: TPX2 siRNA regulates growth and invasion of esophageal cancer cells. Biomed Pharmacother 68: 833-839, 2014.

24. Pazarentzos E and Bivona TG: Adaptive stress signaling in targeted cancer therapy resistance. Oncogene 34: 5599-5606, 2015.

25. Qin M, Liu S, Li A, Xu C, Tan L, Huang J and Liu S: NIK- and IKK $\beta$-binding protein promotes colon cancer metastasis by activating the classical NF- $\mathrm{BB}$ pathway and MMPs. Tumour Biol 37: 5979-5990, 2016

(i) This work is licensed under a Creative Commons Attribution-NonCommercial-NoDerivatives $\quad 4.0$ International (CC BY-NC-ND 4.0) License. 